\title{
S-1 in gastric cancer: a comprehensive review
}

\author{
Yoshiniko MaEhaRa \\ Department of Surgery and Science, Graduate School of Medical Sciences, Kyushu University, 3-1-1 Maidashi, Higashi-ku, \\ Fukuoka 812-8582, Japan
}

\begin{abstract}
The current basic and clinical studies of S-1 (TS-1 ${ }^{\circledR}$ ) were reviewed. $\mathrm{S}-1$ is a novel oral dihydropyrimidine dehydrogenase (DPD) inhibitory fluoropyrimidine (DIF) based on a biochemical modulation of 5-fluorouracil (5-FU); S-1 contains tegafur (FT) and two types of enzyme inhibitor; 5-chloro-2,4dihydroxypyridine (CDHP) and potassium oxonate (Oxo) in a molar ratio of 1:0.4:1. In pharmacokinetic studies, S-1 showed high 5-FU concentration in blood for long periods of time. In a combined analysis of two pivotal late phase II studies in gastric cancer, the overall response rate was $44.6 \%$ $(45 / 101)$, and median survival time and 1-year survival rate were 244 days and $37 \%$, respectively. A postmarketing survey was conducted, and in the interim analysis, tolerability and safety profiles were shown in 3294 patients with gastric cancer. The oral dose form and low incidence of adverse reactions permit treatment on an outpatient basis. To evaluate the survival benefit of $\mathrm{S}-1$ in advanced gastric cancer, a phase III study of S-1 vs 5-FU vs cisplatin (CDDP) plus irinotecan (CPT-11) has been conducted. The effect of S-1 in adjuvant chemotherapy is also promising. Currently, a phase III study of surgery alone vs S-1 in patients with curative resection of gastric cancer is in progress. Further therapeutic benefits are expected to be gained by combining S-1 with other chemotherapeutic agents. Several preliminary results of combination phase I/II studies of S-1 with CDDP or CPT-11 have recently been obtained, and phase II studies are in progress. Thus, S-1 is currently the first candidate as the standard anticancer drug for gastric cancer. Further evaluations by well-controlled clinical trials are still needed.
\end{abstract}

Key words S-1 - Gastric cancer · Comprehensive review

\section{Introduction}

5-Fluorouracil (5-FU) is an antineoplastic drug that is effective against a wide spectrum of solid tumors; it

Offprint requests to: Y. Maehara

Received: September 18, 2002 / Accepted: January 30, 2003 exhibits an antitumor effect not only against gastrointestinal cancer but also against various other cancers, including breast cancer and head and neck cancer [1]. Many methods of 5-FU administration have been explored, and protracted venous infusions of 5-FU led to higher response rates and less toxicity than bolus administration in colorectal cancer [2,3]. 5-FU is currently widely used for the treatment of gastric cancer, and the clinical advantages of administration by continuous intravenous infusion have been reported [4]. However, infusional 5-FU requires intravenous infusion and infusion pumps. An attractive alternative method of delivering protracted 5-FU is through daily oral administration. Oral doses can be given on an ambulatory basis and are preferable from the viewpoint of patients' quality of life (QOL). S-1 is a novel oral fluoropyrimidine derivative based on a biochemical modulation of 5FU. We reviewed basic and clinical data on S-1, which may be called the ultimate antineoplastic drug of the 5FU series, with enhanced effects and reduced adverse reactions.

Novel oral dihydropyrimidine dehydrogenase (DPD) inhibitory fluoropyrimidine (DIF): S-1

\section{Mechanism of action and concept of S-1}

S-1, a new oral antitumor agent, was designed based on the theory of biochemical modulation of 5-FU. In S-1, tegafur (FT) is combined with two classes of enzyme inhibitor, 5-chloro-2,4-dihydroxypyridine (CDHP) and potassium oxonate (Oxo), at a molar ratio of FT: CDHP: Oxo $=1: 0.4: 1$ [5]. The chemical structure of each ingredient is shown in Fig. 1.

FT administered orally is absorbed stably in the small intestine, shows good bioavailability and sustained release, and is slowly converted to 5-FU in vivo, mainly by the liver microsomal P-450 drug-metabolizing enzyme 
<smiles>O=c1[nH]c(=O)n([C@H]2CCCO2)cc1F</smiles><smiles>Oc1cc(O)c(Cl)cn1</smiles>
FT 1<smiles>O=c1nc([N+](=O)[O-])[nH]c(=O)[nH]1</smiles>

Fig. 1. Chemical structure of S-1. FT, Tegafur; CDHP, 5chloro-2,4-dihydroxypyridine; Oxo, potassium oxonate

[6]. However, approximately $80 \%-90 \%$ of $5-\mathrm{FU}$ is degraded by liver DPD, converted to F- $\beta$-alanine, and excreted in urine [7]. The small remaining amount undergoes anabolism, and exhibits antitumor activity through such actions as the inhibition of thymidylate synthetase (TS) by fluorodeoxyuridine monophosphate (FdUMP), an active metabolite, and dysfunction of RNA by incorporation of fluorouridine triphosphate (FUTP) into RNA in tumor tissue. As is clear from the above, it is essential for the effective utilization of 5-FU to arrest the degradation of 5-FU and to increase fluoronucleotides in tumor cells. A series of studies of the substrates for DPD showed that uracil inhibited DPD to enhance the effect of FT. On the basis of this, the oral antitumor drug UFT (FT combined with uracil in a ratio of 1:4) was developed [8]. UFT was confirmed to show an antitumor effect against gastrointestinal and other solid tumors, and a number of clinical reports have been published concerning its effect on gastric cancer [9]. Recently, UFT was found in the West to show favorable results when used in combination with leucovorin in the treatment of advanced colorectaln cancer $[10,11]$. Studies of DPD inhibition were conducted for the development of an ideal drug, which culminated in the discovery of CDHP. CDHP, a reversible competitive inhibitor of DPD, is a pyrimidine derivative with inhibitory activity approximately 180 times more potent than that of uracil, and a Ki of $3.6 \times 10^{-7} \mathrm{M}$ [12] (Fig. 2). Thus, CDHP shows high affinity to DPD, and thereby 5-FU can be retained for longer at higher concentrations in the bloodstream by combining CDHP with FT [13]. Takechi et al. [14] demonstrated that CDHP inhibited 5-FU degradation and enhanced 5-FU cytotoxicity in human tumor cells in vitro, also suggesting that $\mathrm{CDHP}$ inhibits degradation of $5-\mathrm{FU}$ in the tumor. At the same time, F- $\beta$-alanine, the main catabolite of 5-FU, is reduced, which leads to a reduction in toxicities such as neurotoxicity [15]. Sobrero et al. [16] proposed a new classification of fluoropyrimidines with DPD inhibitory activity as DPD inhibitory
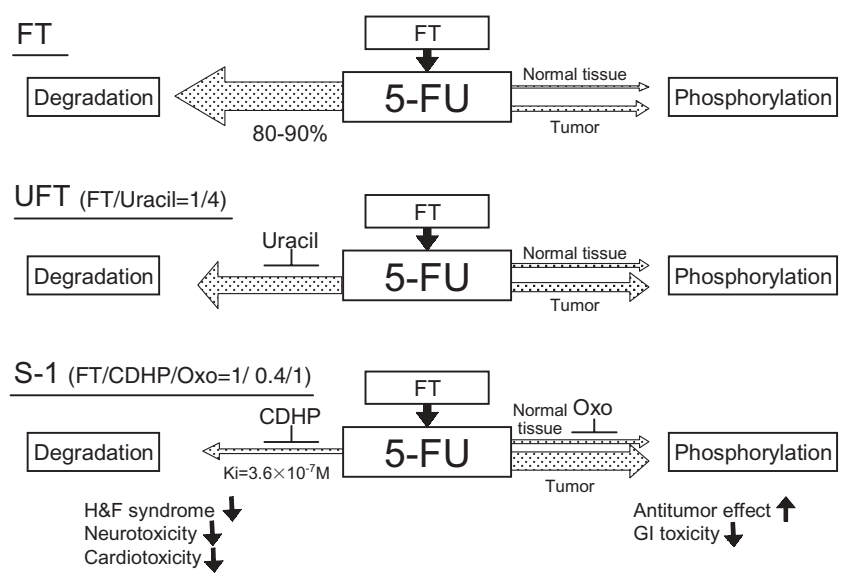

Fig. 2. Basic research for development of dihydropyrimidine dehydrogenase (DPD) inhibitory fluoropyrimidines (DIF). 5$F U$, 5-Fluorouracil; $H \& F$, head and foot; $G I$, gastrointestinal

fluoropyrimidines (DIF), a group which includes UFT and S-1.

To reduce adverse reactions, it is considered necessary to reduce fluoronucleotides in the cells of the gastrointestinal mucosa and bone marrow. When Oxo was orally administered and its organ distribution was studied, it was found to be distributed at high concentrations in the small and large bowels, and was extremely scarce in the tumor. Thus, Oxo co-administered orally with 5-FU specifically inhibits the phosphorylation of 5FU to fluoropyrimidine monophosphate (FUMP) catalyzed by orotate phosphoribosyl transferase (OPRT) within the gastrointestinal mucosal cells, and thereby reduces its gastrointestinal toxicity [17]. Furthermore, it was reported that Oxo, distributed in oral mucosa cells, modulated the occurrence of diarrhea and vomiting in dogs [18]. The optimal molar ratio of the three components of S-1 was defined using tumor-bearing rats as initial preclinical models [5]. In a nude rat system with several human tumor xenografts, S-1 exhibited excellent antitumor efficacy, and marked tumor shrinkage effects were observed in all five gastric tumors [19]. Accordingly, S-1 reduces neurotoxicity and gastrointestinal toxicity (diarrhea, nausea, and vomiting), and augments antitumor activity (Fig. 3).

\section{Clinical studies in gastric cancer}

\section{Phase I clinical trials}

An initial phase I study of S-1 started in 1992 in Japan, and two administration methods, once and twice daily, were evaluated [20].

In once-daily administration, pharmacokinetics and safety were investigated in dose escalation studies with 


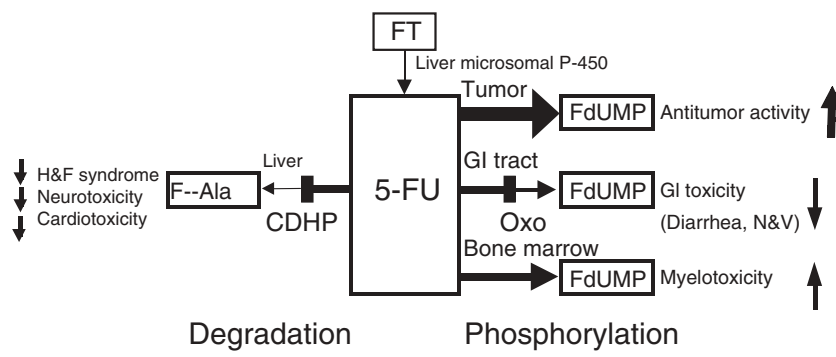

Fig. 3. Biological action of S-1. F- $\beta$-Ala, F- $\beta$-Alanine; $F d$ $U M P$, fluorodeoxyuridine monophosphate; $N \& V$, nousea and vomiting

single doses of 25, 50, 100, 150, and $200 \mathrm{mg} /$ body. Then, once-daily administration of the same doses was conducted for 28 days. The twice-daily administration regimen was carried out for 28 consecutive days with dose escalation from $50 \mathrm{mg}$ to $75 \mathrm{mg}$ and $100 \mathrm{mg} /$ body twice daily. As a result, the maximum allowable dose (MAD) of S-1 was determined to be $50-200 \mathrm{mg} /$ body per day in the once-a-day regimen and $75-100 \mathrm{mg} /$ body in the twice-a-day regimen. Dose-limiting toxicity (DLT) was myelosuppression, mainly consisting of leucopenia, in the two regimens. Adverse reactions which caused discontinuation were rash and vomiting. Most of these adverse reactions resolved within 14 days after discontinuation. In the pharmacokinetic study, the blood concentration of 5-FU after a single administration of S-1 increased dose-dependently and was maintained at a high value for $12 \mathrm{~h}$. Based on these findings, the recommended dosage and administration in early phase II studies were determined to be twice-daily administration of $75 \mathrm{mg} /$ body for 28 consecutive days, with a 14day washout period.

\section{Phase II clinical trials}

Early phase II studies of S-1 were conducted in patients with gastric, colorectal, breast, head and neck, and lung cancers [21-25]. S-1 was initially administered at $75 \mathrm{mg} /$ body twice daily for 28 days, followed by a 14-day washout period. However, because of rash, diarrhea, and severe myelosuppression, the dose of S-1 was reduced to $50 \mathrm{mg} /$ body twice daily. Twenty-eight gastric cancer patients were evaluated. Nine of these patients had been treated previously with other anticancer drugs. Objective responses were seen in 15 of the 28 patients, with a response rate of $54 \%$. Because $75 \mathrm{mg}$ twice daily was associated with skin rash, severe myelosuppression and diarrhea, the actual dose given was calculated from the patient's body surface area (BSA). It was shown that the rate of discontinuation of administration due to such adverse reactions was markedly lower in patients given $\mathrm{S}-1$ at $90 \mathrm{mg} / \mathrm{m}^{2}$ or less. Therefore, $80 \mathrm{mg} / \mathrm{m}^{2}$ $\left(40 \mathrm{mg} / \mathrm{m}^{2}\right.$ twice daily after meals) was set as the stan-

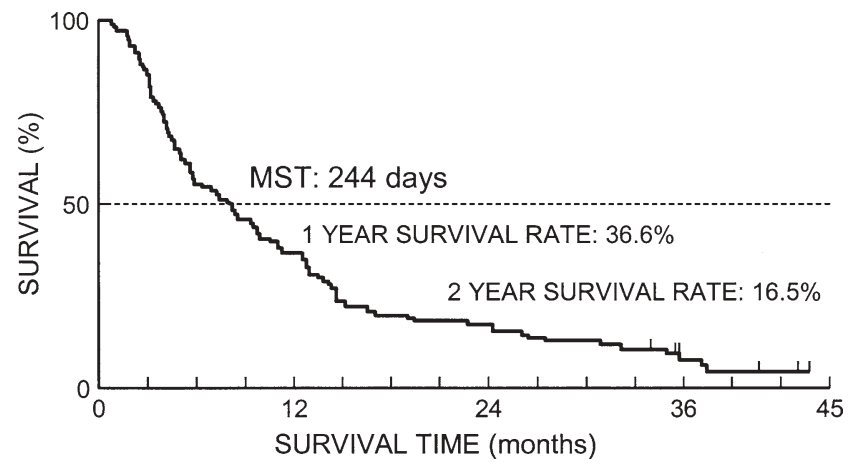

Fig. 4. Survival curve by combined analysis of two pivotal phase II studies of S-1 in gastric cancer $(n=101)$. MST, Median survival time

dard dose in late phase II studies in consideration of the safety profile. Three dose levels, assigned according to the patients' BSA, were used as follows: BSA less than $1.25 \mathrm{~m}^{2}, 80 \mathrm{mg} /$ body per day; BSA $1.25 \mathrm{~m}^{2}$ to less than $1.5 \mathrm{~m}^{2}, 100 \mathrm{mg} /$ body per day; and BSA $1.5 \mathrm{~m}^{2}$ or more, $120 \mathrm{mg} /$ body per day.

Two pivotal late phase II studies of S-1 in advanced gastric cancer were conducted concurrently [26,27]. The eligibility criteria of these trials were the same, as follows: measurable or evaluable gastric cancer with histological proof, performance status (PS) $0-2$, age less than 75 , no prior chemotherapy, adequate organ functions, and written informed consent. S-1 was administered orally twice daily after meals at a standard dose of $80 \mathrm{mg} / \mathrm{m}^{2}$ per day. One course consisted of consecutive administration for 28 days and a 14-day washout period. Administration was repeated until disease progression or unacceptable toxicities. The response rates in these studies were 49\% (25/51) and 40\% (20/50), respectively. In a combined analysis of the two studies, the overall response rate was $44.6 \%(45 / 101)$ and the $95 \%$ confidence interval (CI) was $35.9 \%-62.3 \%$. By site, the response rate was $33.8 \%(25 / 74)$ for primary lesions, $36.4 \%(16 / 44)$ for liver metastasis, 51.5\% (34/66) for lymph node metastasis, and $16.7 \%$ (1/6) for lung metastasis. The median time to response was 35 days (range, 15-123 days) and the median total response period (from the start of administration to the onset of progression) was 158 days (range, 64-490 days). The median survival time (MST), 1-year survival rate, and 2year survival rate were 244 days, $37 \%$, and $17 \%$, respectively (Fig. 4). Toxicities were generally mild. Major toxicities over grade 3 were leucopenia ( $2 \%)$, neutropenia $(5 \%)$, anemia $(6 \%)$, and diarrhea $(2 \%)$. S-1 appeared to be very well tolerated. Table 1 shows a summary of phase II studies of S-1 in gastric cancer. Table 2 shows the activity of approved single agents in advanced gastric cancer. The response rate for S-1 in 
Table 1. Phase II studies of S-1 in gastric cancer

\begin{tabular}{|c|c|c|c|c|c|c|c|c|c|}
\hline Phase & $\begin{array}{l}\text { S-1 daily } \\
\text { dose }\end{array}$ & $\begin{array}{c}\text { Prior } \\
\text { chemotherapy }\end{array}$ & $\begin{array}{l}\text { Eligible } \\
\text { patients }\end{array}$ & $\mathrm{CR}$ & PR & $\mathrm{NC}$ & PD & NE & $\begin{array}{c}\text { Response } \\
\text { rate (\%) }\end{array}$ \\
\hline $\begin{array}{l}\text { Early phase II } \\
\text { Late phase II }\end{array}$ & $100-150 \mathrm{mg} /$ body & Yes/no & 28 & 0 & 15 & 4 & 6 & 3 & 53.6 \\
\hline Group T & $80 \mathrm{mg} / \mathrm{m}^{2}$ & No & 51 & 1 & 24 & 11 & 13 & 2 & 49.0 \\
\hline Group K & $80 \mathrm{mg} / \mathrm{m}^{2}$ & No & 50 & 0 & 20 & 16 & 13 & 1 & 40.0 \\
\hline
\end{tabular}

CR, Complete response; PR, partial response; NC, no change; PD, progressive disease; NE, not evaluable; S-1, tegafur + 5-chloro-2,4dihydroxypyridine (CDHP) and potassium oxonate (Oxo), at a molar ratio of FT: CDHP: Oxo of 1:0.4:1

Table 2. Single-agent activity in advanced gastric cancer

\begin{tabular}{|c|c|c|c|c|c|c|c|}
\hline \multirow[b]{2}{*}{ Drug } & \multirow{2}{*}{$\begin{array}{l}\text { Eligible } \\
\text { cases }\end{array}$} & \multirow{2}{*}{$\begin{array}{l}\text { Assessable } \\
\text { cases }\end{array}$} & \multirow[b]{2}{*}{ CR } & \multirow[b]{2}{*}{ PR } & \multicolumn{2}{|c|}{ Response rate (\%) } & \multirow[b]{2}{*}{ Author } \\
\hline & & & & & /Eligible & /Assessable & \\
\hline UFT & 286 & 188 & 3 & 49 & 18.2 & 27.7 & Takiuchi [9] \\
\hline 5'-DFUR & 161 & 140 & 1 & 19 & 12.4 & 14.3 & Niitani [28] \\
\hline CDDP & 71 & 68 & 0 & 13 & 18.3 & 19.1 & Ishibiki [29] \\
\hline CPT-11 & 76 & 60 & 0 & 14 & 18.4 & 23.3 & Futatsuki [30] \\
\hline \multirow[t]{2}{*}{ Docetaxel } & 66 & 59 & 1 & 13 & 21.2 & 23.7 & Taguchi [31] \\
\hline & 63 & 59 & 1 & 13 & 22.2 & 23.7 & Mai [32] \\
\hline \multirow[t]{2}{*}{ Paclitaxel } & 32 & 32 & 0 & 9 & 28.1 & 28.1 & Yamaguchi [33] \\
\hline & 60 & 60 & 0 & 14 & 23.3 & 23.3 & Yamada [34] \\
\hline \multirow[t]{2}{*}{ S-1 } & 51 & 51 & 1 & 24 & 49.0 & 49.0 & Sakata [26] \\
\hline & 50 & 50 & 0 & 20 & 40.0 & 40.0 & Koizumi [27] \\
\hline
\end{tabular}

CR, complete response; PR, partial response; UFT, Tegafur + uracil (molar ratio 1:4); 5'DFUR, 5'-deoxy-5-fluorouridine; CDDP, cisplatin; CPT-II, irinotecan

gastric cancer was over $40 \%$, which exceeded the response rates for other drugs.

\section{Pharmacokinetics}

A pharmacokinetic study of S-1 was conducted by Hirata et al. [35] to investigate 5-FU, FT, CDHP, and Oxo, after administration of S-1 at a standard dose of $80 \mathrm{mg} / \mathrm{m}^{2}$ per day $\left(40 \mathrm{mg} / \mathrm{m}^{2}\right.$ twice daily). In 28 -day consecutive administration, the standard dose was given daily in two divided doses. Ten patients were evaluated. Pharmacokinetic parameters of plasma 5-FU were as follows: $\mathrm{C}_{\max }, 113.7 \pm 40.5 \mathrm{ng} / \mathrm{ml} ; \mathrm{T}_{\max }, 3.4 \pm 1.3 \mathrm{~h}$; AUC $_{0-48 \mathrm{~h}}, 609.0 \pm 170.2 \mathrm{ng} \cdot \mathrm{h} / \mathrm{ml} ;$ and $\mathrm{T}_{1 / 2}, 2.9 \pm 1.1 \mathrm{~h}$. There were no fluctuations in pharmacokinetics and no drug accumulation with this schedule.

Yamada et al. [36] compared the pharmacokinetics of 5 -FU and $\mathrm{F}-\beta$-alanine in patients receiving protracted venous infusion (PVI) of 5-FU and oral S-1. Eight patients with gastric cancer received $5-\mathrm{FU}$ at $250 \mathrm{mg} / \mathrm{m}^{2}$ by PVI for 5 days (Lokich regimen), one of the standard administration schedules of 5-FU for gastrointestinal cancer. After a washout period of 9 days, S-1 was administered at $80 \mathrm{mg} / \mathrm{m}^{2}\left(40 \mathrm{mg} / \mathrm{m}^{2}\right.$ twice daily) for 28 days. Plasma concentrations of 5 -FU and $\mathrm{F}$ - $\beta$-alanine were measured in the same patients. The $\mathrm{C}_{\max }$ of 5-FU was $94.5 \pm 19.5 \mathrm{ng} / \mathrm{ml}$ for PVI 5-FU and $209.1 \pm 56.2 \mathrm{ng} / \mathrm{ml}$ for S-1, and the $\mathrm{AUC}_{0-10 \mathrm{~h}}$ of 5 -FU was $731.6 \pm$ $161.7 \mathrm{ng} \cdot \mathrm{h} / \mathrm{ml}$ for PVI 5 -FU and $1244.6 \pm 262.4 \mathrm{ng} \cdot \mathrm{h} / \mathrm{ml}$ for S-1. The $\mathrm{AUC}_{0-10 \mathrm{~h}}$ of $\mathrm{F}-\beta$-alanine was $8441.7 \pm$ $2825.7 \mathrm{ng} \cdot \mathrm{h} / \mathrm{ml}$ for PVI 5 -FU and $1458.3 \pm 573.8 \mathrm{ng} \mathrm{h} / \mathrm{ml}$ for S-1. Thus, although the $\mathrm{C}_{\max }$ and AUC of 5-FU values were higher for S-1 than for PVI 5-FU, the plasma concentration of F- $\beta$-alanine, the main metabolite of 5FU, was significantly higher for PVI 5-FU than for S-1.

\section{Combination clinical trials}

Ohtsu et al. [37] reported the results of a combination phase I/II study of S-1 plus cisplatin (CDDP) in gastric cancer. S-1 was administered orally at $80 \mathrm{mg} / \mathrm{m}^{2}$ per day $\left(40 \mathrm{mg} / \mathrm{m}^{2}\right.$ twice daily) for 21 consecutive days, and CDDP was infused over $2 \mathrm{~h}$ (levels 1,2 , and $3 ; 60,70$, and $80 \mathrm{mg} / \mathrm{m}^{2}$ ) on day 8 . This schedule was repeated every 4-5 weeks. A total of 25 patients who had no previous chemotherapy, 12 for phase I and 13 additional patients for phase II, were registered. Level $2\left(70 \mathrm{mg} / \mathrm{m}^{2}\right.$ of CDDP) was determined as the maximum tolerated dose (MTD) and the dose at level $1\left(60 \mathrm{mg} / \mathrm{m}^{2}\right.$ of CDDP) was used for the subsequent trial. Objective responses were seen in 19 of the 25 patients, with a response rate of $76 \%$. A phase III study is ongoing to evaluate the survival benefit of this combination therapy in gastric cancer. 
Combination phase I studies of S-1 plus irinotecan (CPT-11) in gastric cancer were conducted. Narahara et al. [38] reported a phase I study of S-1 plus biweekly CPT-11 in gastric cancer. S-1 was administered orally at $80 \mathrm{mg} / \mathrm{m}^{2}$ per day for 21 consecutive days, and CPT-11 was infused over $90 \mathrm{~min}$ (levels $1,2,3,4$, and 5; 40, 60, 80,100 , and $120 \mathrm{mg} / \mathrm{m}^{2}$ ) on day 1 and day 15 . Nineteen patients were registered in this study. Level $4(100 \mathrm{mg}$ / $\mathrm{m}^{2}$ of CPT-11) was determined as the MTD and the recommended dose of CPT-11 was determined to be $80 \mathrm{mg} / \mathrm{m}^{2}$ (level 3). The overall response rate was $56 \%$ (10/18). Komatsu et al. [39] reported a study in which S1 was administered orally at $80 \mathrm{mg} / \mathrm{m}^{2}$ per day $\left(40 \mathrm{mg} / \mathrm{m}^{2}\right.$ twice a day) for 14 consecutive days, and CPT-11 was infused over $90 \mathrm{~min}$ (levels 1, 2, and 3; 100, 125, and $150 \mathrm{mg} / \mathrm{m}^{2}$ ) on day 1 and day 15 . This schedule was repeated every 4 weeks. Fifteen patients were registered in this study. The recommended dose for this combination was determined to be CPT-11 $125 \mathrm{mg} / \mathrm{m}^{2}$ (level 2). The overall response rate was 53\% (8/15). Phase II studies have already started in both study groups.

\section{Postmarketing survey and clinical practice}

Manufacturing approval for S-1 was granted in January 1999. The postmarketing surveillance was conducted for 1 year, with a target population of 3000 cases, and the tolerability and safety of S-1 for gastric cancer were evaluated. In the interim analysis of the postmarketing survey in Japan, the tolerability and the safety profile of S-1 were assessed in 3294 patients with gastric cancer [40]. S-1 was basically administered at a standard dose of $80 \mathrm{mg} / \mathrm{m}^{2}$ per day $\left(40 \mathrm{mg} / \mathrm{m}^{2}\right.$ twice daily after meals) on 28 consecutive days, followed by a 14-day washout period. The number of cycles actually administered was as follows: two or more courses, 72\% (2372/3294) and three or more courses, 47\% (1534/3294). In these surveys, the overall incidence of adverse reactions was
$74 \%$ (2441 of 3294 patients). Frequent adverse events in the late phase II study and postmarketing surveillance are listed in Table 3. Major adverse events and their frequencies were similar in the above two studies, and the most common toxicity was hematological toxicities such as leucopenia. Multivariate analysis revealed that grade 3 or worse hematological toxicities occurred significantly more frequently in patients with impairment of renal function. Ikeda et al. [41] investigated the pharmacokinetics of S-1 in an experimental renalfailure animal model and in patients with impaired renal function. There were higher and longer-lasting 5-FU concentrations, and subsequent values for AUC increased, in the experimental renal-failure model and in patients with renal impairment, due to the retention of CDHP. These findings demonstrated that the administration of S-1 to patients with impaired renal function might require individualized dosing and pharmacokinetic monitoring.

Many reports are available on the utility of S-1 in clinical practice, and, as well, there are case reports concerning S-1 used in patients with gastric cancer at various evaluable sites [42-48]; these studies testify to the utility of S-1 in medical practice.

\section{Future perspectives}

The response rate for S-1 in gastric cancer is over $40 \%$ (which exceeds the response rates for other approved drugs that remain at around $20 \%$ ), and is comparable to the previously reported response rates for representative combination chemotherapies such as fluorouracil plus CDDP regimens [49-51]. These data suggest that S-1 can be used as a first-line drug in chemotherapy for gastric cancer. Moreover, S-1 administered orally has a great advantage in that it can be used on an ambulatory basis to improve the QOL of patients. Although it is necessary to verify the life-prolonging effect of S-1 in a

Table 3. Frequent adverse events in a late phase II study and postmarketing survey

\begin{tabular}{|c|c|c|c|c|}
\hline \multirow[b]{2}{*}{ Adverse effect } & \multicolumn{2}{|c|}{ Late phase $\mathrm{II}^{\mathrm{a}}$} & \multicolumn{2}{|c|}{ Postmarketing survey } \\
\hline & $\geq \mathrm{G} 1(\%)$ & $\geq \mathrm{G} 3(\%)$ & $\geq \mathrm{G} 1(\%)$ & $\geq \mathrm{G} 3(\%)$ \\
\hline Leukopenia & 44.6 & 2.0 & 25.9 & 2.7 \\
\hline Neutropenia & 43.6 & 5.0 & 21.2 & 6.2 \\
\hline Anemia & 34.7 & 5.9 & 24.6 & 6.3 \\
\hline Thrombocytopenia & 7.9 & 0 & 8.5 & 1.6 \\
\hline Diarrhea & 9.9 & 2.0 & 16.4 & 2.0 \\
\hline Anorexia & 19.8 & 0 & 26.1 & 6.2 \\
\hline Nausea/vomiting & 8.9 & 0 & 19.0 & 2.1 \\
\hline Stomatitis & 10.9 & 0 & 12.7 & 1.4 \\
\hline
\end{tabular}

G, Grade

${ }^{\text {a }}$ Combined analysis of two pivotal late phase II studies $(n=101)$

${ }^{\mathrm{b}}$ Interim analysis of postmarketing survey $(n=3294)$ 
phase III study in the future, the ongoing phase III study of 5-FU vs S-1 vs CPT-11 plus CDDP by the Japan Clinical Oncology Group (JCOG) shows considerable promise for S-1. The effect of S-1 in neoadjuvant and adjuvant chemotherapy is also promising. Currently, an ongoing large-scale randomized clinical trial (required sample size, 1000 patients) is aimed at comparing surgery alone vs 1 -year treatment with $\mathrm{S}-1$ in patients who had undergone curative resection for stage II, IIIa, or IIIb gastric cancer. For further enhancement of the efficacy, combination chemotherapy with other drugs, including CDDP, CPT-11, and taxanes, such as docetaxel and paclitaxel, is expected to yield good results. Further evaluation by clinical trials is also required.

On the basis of this review of basic and clinical studies to date, $\mathrm{S}-1$ is believed to be the ultimate fluoropyrimidine, based on the biochemical modulation of 5-FU. S1 is currently considered to be the first candidate as the standard drug for gastric cancer and should be used as first-line chemotherapy. Through the accumulation of evidence from ongoing and future clinical trials, it is certain that chemotherapy including S-1 will become state-of-the-art treatment for gastric cancer in future.

Acknowledgments I thank Dr. T. Taguchi, Dr. M. Kurihara, Dr. W. Koizumi, Dr. Y. Sakata, Dr. A. Otsu, and Dr. F. Nagashima for providing us with reports and reference materials.

\section{References}

1. Grem JL. 5-Fluorouracil: forty-plus and still ticking. A review of its preclinical and clinical development. Invest New Drugs 2000; 18:299-313.

2. Meta Analysis Group in Cancer. Efficacy of intravenous continuous infusion of fluorouracil compared with bolus administration in advanced cancer. J Clin Oncol 1998;16:301-8.

3. Meta Analysis Group in Cancer. Toxicity of fluorouracil in patients with advanced gastric cancer: effect of administration schedule and prognostic factors. J Clin Oncol 1998;16:3537-41.

4. Moynihan T, Hansen R, Anderson T, Quebbeman E, Beatty P, Ausman R, et al. Continuous 5-fluorouracil infusion in advanced gastric carcinoma. Am J Clin Oncol 1998;11:461-4.

5. Shirasaka T, Shimamoto Y, Ohshimo H, Yamaguchi M, Kato T, Yonekura K, et al. Development of a novel form of an oral 5fluorouracil derivative (S-1) directed to the potentiation of the tumor selective cytotoxicity of 5-fluorouracil by two biochemical modulators. Anticancer Drugs 1996;7:548-57.

6. Toide H, Akiyoshi H, Minato Y, Okuda H, Fujii S. Comparative studies on the metabolism of 2-(tetrahydrofuryl)-5-fluorouracil and 5-fluorouracil. Gann 1977;68:553-60.

7. Fujii S, Shimamoto Y, Ohshimo H, Imaoka T, Motoyama M, Fukushima M, et al. Effects of the plasma concentration of 5 -fluorouracil and the duration of continuous venous infusion of 5-fluorouracil with an inhibitor of 5-fluorouracil degradation on Yoshida sarcomas in rats. Jpn J Cancer Res 1989;80:16772.

8. Fujii S, Kitano S, Ikenaka K, Fukushima M, Shirasaka T. Coadministration of uracil or sytosine on antitumor activity of FT207 or 5-FU derivatives. Jpn J Cancer Chemother 1979;6:1097-103.
9. Takiuchi H, Ajani JA. Uracil-Tegafur in gastric carcinoma: a comprehensive review. J Clin Oncol 1998;16:2877-85.

10. Carmichael J, Popiela T, Radstone D, Falk S, Borner M, Oza A, et al. Randomized comparative study of tegafur/uracil and oral leucovorin versus parenteral fluorouracil and leucovorin in patients with previously untreated metastatic colorectal cancer. J Clin Oncol 2002;20:3617-27.

11. Douillard JY, Hoff PM, Skillings JR, Eisenberg P, Davidson N, Harper P, et al. Multicenter phase III study of uracil/tegafur and oral leucovorin versus fluorouracil and leucovorin in patients with previously untreated metastatic colorectal cancer. J Clin Oncol 2002;20:3605-16.

12. Tatsumi K, Fukushima M, Shirasaka T, Fujii S. Inhibitory effects of pyrimidine, barbituric acid and pyridine derivatives on 5fluorouracil degradation in rat liver extracts. Jpn J Cancer Res 1987;78:748-55.

13. Shirasaka T, Nakano K, Takechi T, Satake H, Uchida J, Fujioka A, et al. Antitumor activity of $1 \mathrm{M}$ tegafur-0.4 M 5-chloro-2,4dihydropyrimidine-1 $\mathrm{M}$ potassium oxonate (S-1) against human colon carcinoma orthotopically implanted into nude rats. Cancer Res 1996;56:2602-6.

14. Takechi T, Fujioka A, Matsushima E, Fukushima M. Enhancement of the antitumor activity of 5-fluorouracil (5-FU) by inhibiting dihydropyrimidine dehydrogenase activity (DPD) using 5-chloro-2,4-dihydroxypyrimidine (CDHP) in human tumour cells. Eur J Cancer 2002;38:1271-7.

15. Foenig H, Patel A. Biochemical basis for fluorouracil neurotoxicity: the role of Krebs cycle inhibition by fluoroacetate. Arch Neurol 1970;23:155-60.

16. Sobrero A, Kerr D, Glimelius B, Cutsem EV, Milano G, Pritchard DM, et al. New directions in the treatment of colorectal cancer: a look to the future. Eur J Cancer 2000;36:559-66.

17. Shirasaka T, Shimamoto Y, Fukushima M. Inhibition by oxonic acid of gastrointestinal toxicity of 5-fluorouracil without loss of its antitumor activity in rats. Cancer Res 1993;53:4004-9.

18. Kato T, Shimamoto Y, Uchida J, Ohshimo H, Abe M, Shirasaka $\mathrm{T}$, et al. Possible regulation of 5-fluorouracil-induced neuro- and oral toxicities by two biochemical modulators consisting of S-1, a new oral formulation of 5-fluorouracil. Anticancer Res 2001;21: 1705-12.

19. Fukushima M, Satake H, Uchida J, Shimamoto Y, Kato T, Takechi T, et al. Preclinical antitumor efficacy of S-1: a new oral formulation of 5-fluorouracil on human tumor xenografts. Int $\mathrm{J}$ Oncol 1998;13:693-8.

20. Taguchi T, Inuyama Y, Kanamaru R, Hasegawa K, Akazawa S, Niitani H, et al. Phase I study of S-1. Jpn J Cancer Chemother 1997;24:2253-64.

21. Sugimachi K, Maehara Y, Horikoshi N, Shimada Y, Sakata Y, Mitachi Y, et al. An early phase II study of oral S-1, a newly developed 5-fluorouracil derivative for advanced and recurrent gastrointestinal cancers. Oncology 1999;57:202-10.

22. Ohtsu A, Baba H, Sakata Y, Mitachi Y, Horikoshi N, Sugimachi $\mathrm{K}$, et al. Phase II study of S-1, a novel oral fluoropyrimidine derivative, in patients with metastatic colorectal carcinoma. Br J Cancer 2000;83:141-5.

23. Taguchi $\mathrm{T}$, Morimoto $\mathrm{K}$, Horikoshi $\mathrm{N}$, Takashima S, Toge $\mathrm{T}$, Kimura M, et al. An early phase II clinical study of S- 1 in patients with breast cancer. Jpn J Cancer Chemother 1998;25:103543.

24. Inuyama Y, Kida A, Tsukuda M, Kohno N, Satake B. Early phase II study of S-1 in patients with advanced head and neck cancer. Jpn J Cancer Chemother 1998;25:1151-8.

25. Furuse K, Kawahara M, Hasegawa K, Kudoh S, Takada M, Sugiura T, et al. Early phase II study of S-1, a new oral fluoropyrimidine, for advanced non-small-cell lung cancer. Int $\mathbf{J}$ Clin Oncol 2001;6:236-41.

26. Sakata Y, Ohtsu A, Horikoshi N, Sugimachi K, Mitachi Y, Taguchi T. Late phase II study of novel oral fluoropyrimidine anticancer drug S-1 (1 M tegafur- $0.4 \mathrm{M}$ gimestat- $1 \mathrm{M}$ otastat po- 
tassium) in advanced gastric cancer patients. Eur J Cancer 1998;34:1715-20.

27. Koizumi W, Kurihara M, Nakano S, Hasegawa K. Phase II study of S-1, a novel oral derivative of 5-fluorouracil, in advanced gastric cancer. Oncology 2000;58:191-7.

28. Niitani H, Kurihara M, Saito T, Nakao I, Abe O, Urushizaki I, et al. Phase II study of $5^{\prime}$-deoxy-5-fluorouridine (5'-DFUR) on patients with malignant cancer - multi-institutional cooperative study. Jpn J Cancer Chemother 1985;12:2044-51.

29. Ishibiki K, Kumai K, Kodaira S, Abe O, Yamamoto K, Ouchi T, et al. Phase II study with cisplatin in advanced stomach and colon cancer. Jpn J Cancer Chemother 1989;16:3185-93.

30. Futatsuki K, Wakui A, Nakao I, Sakata Y, Kambe M, Shimada Y, et al. Late phase II study of irinotecan hydrochloride (CPT-11) in advanced gastric cancer. Jpn J Cancer Chemother 1994;21:1033-8.

31. Taguchi T, Sakata Y, Kanamaru R, Kurihara M, Suminaga M, Ota J, et al. Late phase II clinical study of RP56976 (docetaxel) in patients with advanced/recurrent gastric cancer: a Japanese Cooperatative Study Group Trial (Group A). Jpn J Cancer Chemother 1998;25:1915-24.

32. Mai M, Sakata Y, Kanamaru R, Kurihara M, Suminaga M, Ota J, et al. A late phase II clinical study of RP56976 (docetaxel) in patients with advanced or recurrent gastric cancer: a Japanese Cooperatative Study Group Trial (Group B). Jpn J Cancer Chemother 1999;26:487-96.

33. Yamaguchi K, Tada M, Horikoshi N, Otani T, Takiuchi H, Saitoh $\mathrm{S}$, et al. Phase II study of paclitaxel with 3 -h infusion in patients with advanced gastric cancer. Gastric Cancer 2002;5:90-5.

34. Yamada Y, Shirao K, Ohtsu A, Boku N, Hyodo I, Saitoh H, et al. Phase II trial of paclitaxel by 3-hour infusion for advanced gastric cancer with short premedication for prophylaxis of paclitaxelassociated hypersensitivity reactions. Ann Oncol 2001;12:1133-7.

35. Hirata K, Horikoshi N, Aiba K, Okazaki M, Denno R, Sasaki K, et al. Pharmacokinetic study of S-1, a novel oral fluorouracil antitumor drug. Clin Cancer Res 2000;5:2000-5.

36. Yamada K, Shirao Y, Matsumura K, Muro M, Goto T, Hamaguchi Y, et al. Comparison of 5-fluorouracil and F- $\beta$-alanin pharmacokinetics in patients receiving protracted venous infusion of 5-fluorouracil and oral S-1 (abstract). Proc Am Soc Clin Oncol 2001;20:91a.

37. Ohtsu A, Boku N, Nagashima F, Koizumi W, Tanabe S, Saigenji $\mathrm{K}$, et al. A phase I/II study of S-1 plus cisplatin (CDDP) in patients (pts) with advanced gastric cancer (ACG) (abstract). Proc Am Soc Clin Oncol 2001;20:165a.

38. Narahara H, Takiuchi H, Tsujinaka T, Furukawa H, Taguchi T. Phase I study of CPT-11 plus S-1 in patients with metastatic gastric cancer (abstract). Proc Am Soc Clin Oncol 2002;21:170a.
39. Komatsu Y, Takeda H, Masaaki T, Kato T, Tateyama M, Miyagishima $\mathrm{T}$, et al. A phase I and PK study of S-1 and irinotecan (CPT-11) in patients with advanced gastric cancer (AGC) (abstract). Proc Am Soc Clin Oncol 2002; 21:171a.

40. Nagashima F, Ohtsu A, Boku N, Yoshida S, Itoh K, Sano M. Japanese nation-wide post marketing survey of S-1 in patients with advanced gastric Cancer. $4^{\text {th }}$ International Conference on Biology, Prevention and Treatment of Gastrointestinal Malignancies, September 6-8, 2001, Koln, Germany.

41. Ikeda M, Furukawa H, Imamura H, Shimizu J, Ishida H, Masutani S, et al. Pharmacokinetic study of S-1, a novel oral fluorouracil antitumor agent in animal model and in patients with impaired renal function. Cancer Chemother Pharmacol 2002;50:25-32.

42. Yoshikawa T, Kanari M, Tsuburaya A, Kobayashi O, Sairenji M, Motohashi $\mathrm{H}$, et al. Advanced gastric carcinoma successfully treated with TS-1 as neoadjuvant chemotherapy. Gastric Cancer 2000;3:171-5.

43. Kurakawa E, Kasuga I, Ishizuka S, Yoshida T, Kunisawa A, Minemura K, et al. Interstitial pneumonia possibly due to a novel anticancer drug, TS-1: first case report. Jpn J Clin Oncol 2001;31: 284-6.

44. Tsukioka Y, Matsumura Y, Hamaguchi T, Goto M, Muro K, Yamada Y, et al. Complete response achieved following administration of S-1 in a patient with adrenal gland metastasis of 5-FUresistant gastric cancer: a case report. Jpn J Clin Oncol 2001;31: 450-3.

45. Osugi H, Takada N, Takemura M, Kaseno S, Lee S, Ueno M, et al. Oral fluoropyrimidine anticancer drug TS-1 for gastric cancer patients with peritoneal dissemination. Oncol Rep 2002;9:811-5.

46. Kobayashi O, Konishi K, Kanari M, Cho H, Yoshikawa T, Tsuburaya A, et al. Unusual survival for more than 2 years with peritoneal metastases of gastric cancer. Gastric Cancer 2002;5:4750 .

47. Iwazawa T, Kinuta M, Yano H, Matsui S, Tamagaki S, Yasue A, et al. An oral anticancer drug, TS-1, enabled a patient with advanced gastric cancer with Virchow's metastasis to receive curative resection. Gastric Cancer 2002;5:96-101.

48. Watanabe S, Tanaka T, Takeuchi T, Takabayashi H, Hirayama Y. Advanced gastric cancer with liver metastases successfully treated with S-1. Int J Clin Oncol 2002;7:326-9.

49. Ajani JA, Ota DM, Jackson DE. Current strategies in the management of locoregional and metastatic gastric cancer. Cancer 1991;67:260-5.

50. Schipper DL, Wagener DJ. Chemotherapy of gastric cancer. Anticancer Drugs 1996;7:137-49.

51. Tahara M, Ohtsu A. Latest progress on chemotherapy for advanced gastric cancer. Jpn J Cancer Chemother 2000;27:2048-58. 